OPEN ACCESS

Edited by:

Mario U. Manto,

Fonds de la Recherche Scientifique,

Belgium

Reviewed by:

Filippo Brighina,

University of Palermo, Italy

Florian Bodranghien,

Université Libre de Bruxelles, Belgium

*Correspondence:

Sheng Tan

tansheng18@126.com

${ }^{+}$Both Yanhua Huang and YeE Li are first authors.

Received: 19 June 2015 Accepted: 08 October 2015 Published: 19 October 2015

Citation:

Huang Y, Li Y, Chen J, Zhou H and Tan S (2015) Electrical stimulation elicits neural stem cells activation: new perspectives in CNS repair.

Front. Hum. Neurosci. 9:586. doi: 10.3389/fnhum.2015.00586

\section{Electrical stimulation elicits neural stem cells activation: new perspectives in CNS repair}

\author{
Yanhua Huang ${ }^{1+}$, YeE Li2t , Jian Chen ${ }^{1}$, Hongxing Zhou ${ }^{1}$ and Sheng Tan ${ }^{1 *}$ \\ 'Department of Neurology, Zhujiang Hospital of Southern Medical University, Guangzhou, China, ${ }^{2}$ Department of Neurology, \\ Dalang Hospital, Dongguan, China
}

Researchers are enthusiastically concerned about neural stem cell (NSC) therapy in a wide array of diseases, including stroke, neurodegenerative disease, spinal cord injury, and depression. Although enormous evidences have demonstrated that neurobehavioral improvement may benefit from NSC-supporting regeneration in animal models, approaches to endogenous and transplanted NSCs are blocked by hurdles of migration, proliferation, maturation, and integration of NSCs. Electrical stimulation (ES) may be a selective non-drug approach for mobilizing NSCs in the central nervous system. This technique is suitable for clinical application, because it is well established and its potential complications are manageable. Here, we provide a comprehensive review of the emerging positive role of different electrical cues in regulating NSC biology in vitro and in vivo, as well as biomaterial-based and chemical stimulation of NSCs. In the future, ES combined with stem cell therapy or other cues probably becomes an approach for promoting brain repair.

Keywords: electrical stimulation, neural stem cells, activation, central nervous system, neural regeneration, repair

\section{INTRODUCTION}

Electrical stimulation (ES) is a kind of modern treatment method, such as electroconvulsive therapy (Sackeim et al., 2000), transcranial magnetic stimulation (TMS), deep-brain stimulation (DBS), vagal nerve stimulation (Smith et al., 2005), epidural stimulation (Jahanshahi et al., 2013), and transcranial direct current stimulation (tDCS). Not only in preclinical but also in clinical studies, ES is widely proposed for use in many neurological and psychiatric disorders. However, the underlying therapeutic mechanisms remain greatly uninvestigated. Research into relation between ES and specific disorders suggests that functional recovery is attributed to following mechanisms, by means of alterations of cortical excitability (Ludemann-Podubecka et al., 2014), modulation of brain inflammatory response (Pienaar et al., 2015), blood-brain barrier

\footnotetext{
Abbreviations: AD, Alzheimer's diseases; BDNF, brain-derived neurotrophic factor; CNS, central nervous system; DBS, deep-brain stimulation; DLPFC, The dorsolateral prefrontal cortex; EA, electroacupuncture; EFs, electrical fields; ES, electrical stimulation; FDA, Food and Drug Administration; FES, Functional Electrical Stimulation; GPi, internal segment of the globus pallidus; IFN- $\gamma$, interferon- $\gamma$; NIES, non-invasive electrical stimulation; NPCs, neural precursor cells; NSC, neural stem cell; PD, Parkinson's disease; STN, subthalamic nucleus; tDCS, transcranial direct current stimulation; TMS, transcranial magnetic stimulation; VEGF, vascular endothelial growth factor; VIM, ventrointermediate nucleus of the thalamus; vmPFC, ventromedial prefrontal cortex.
} 
permeability (Levi et al., 2012), brain perfusion and neuronal apoptosis (Borsody et al., 2014; Wang et al., 2014), and promotion of neural plasticity (Boggio et al., 2011). Neural plasticity mainly includes synapse formation, dendritic structure, and neurogenesis (Lendvai et al., 2000; Nithianantharajah and Hannan, 2006).

Neural stem cells (NSCs) are self-renewing and multipotent cells that can give rise to neurons, astrocytes, and oligodendrocytes. They exist in the subventricular zone (SVZ) of the lateral ventricle and the dentate gyrus subgranular zone (SGZ) of the hippocampus throughout life (Reynolds and Weiss, 1992; Alvarez-Buylla and Lim, 2004). Besides endogenous NSCs, there are also exogenous NSCs, which are derived from other stem cells like embryonic stem cells (Banda et al., 2015), mesenchymal stem cells (Chen et al., 2013) and induced pluripotent stem cells (Nizzardo et al., 2014) when they undergo neural differentiation. On the other hand, it has been reported that somatic cells, such as fibroblasts and astrocytes, have been reprogramed into induced NSCs with specific transcription factors (Ganat et al., 2006; Corti et al., 2012; Han et al., 2012; Thier et al., 2012). NSCs in the central nervous system (CNS) can be activated by various physiological and pathological stimuli, indicating that endogenous NSCs can be a potential therapy for brain tissue repair. In addition, the transplantation of exogenous NSCs has been verified feasible in a broad range of animal disease models (Tang et al., 2014; Salewski et al., 2015; Zhang et al., 2015) and even in certain clinical trials (Chen et al., 2013; Feldman et al., 2014). As they are transplanted or intrinsically activated, NSCs are capable to proliferate, migrate, adopt neural phenotypes, and finally integrate into neural circuits, leading to neural repair. Accordingly, NSC-based technology is a new yet promising approach for ailments in the CNS. In fact, the inadequate availability of endogenous NSCs limits CNS from self-repair in response to diseases or injuries. Similarly, difficulties in the application of NSCs transplants reduce their therapeutic efficacy. Besides well-known issues of immunological rejection, reliable sources and ethical pressure, limited proliferation, migration, differentiation, and viability of NSCs following transplantation are more challenging. For instance, literature has shown that transplanted NSCs survive for maximum several weeks (Jablonska et al., 2010). Einstein et al. (2006) discovered that neural precursor cells (NPCs) generate a few neuronal populations ex vivo and have low efficiency in astrocytes and oligodendrocytes differentiation after being grafted, with 15 and 7\%, respectively. These limitations have impelled research workers to explore optimized and feasible protocols for NSC-based therapies.

Numerous studies have revealed that the ES plays a potential regenerative role in memory (Liu et al., 2015a), depression (Zhang et al., 2014), stroke (Guo et al., 2014), and spinal cord injury (SCI) (Becker et al., 2010) in rat models. These findings may deepen our understanding of cell replacement therapies following CNS insults and then drive the translation of NSC therapies combined with ES from animal experiments into the clinic settings. Thus, we will primarily focus on the use of endogenous and exogenous electrical currents in the development of NSC-based approaches.

\section{ENDOGENOUS ELECTRICAL CURRENTS IN THE CENTRAL NERVOUS SYSTEM}

Endogenous electrical currents have been discovered in the normal and injured brains. These currents play an important role in biological functions, such as promotion of neural tube formation (Hotary and Robinson, 1990), induction of axonal regeneration (Borgens et al., 1980), and guidance of neural cell migration (Cao et al., 2013). For instance, Cao et al. (2013) detected that endogenous electrical currents $(3-5 \mathrm{mV} / \mathrm{mm})$ flow from the SVZ to olfactory bulb. Then they identified the applied electrical currents of physiological strength as directional signals for neuroblast migration in vitro and in brain slices. Data showed that directedness value of migration in electric field group is 2-2.5-folds higher than that in control group, which does not respond to electric currents. The directedness value was used to quantify directional migration of neuroblasts toward the cathode. Endogenous electrical currents also occur in pathological conditions like SCI or epilepsy. Epilepsy is characterized by nonsynchronous brain electrical activity. The abnormal brain electrical activity not only results in recurrent seizure activity but also an increase of $163 \%$ in number of precursor populations in the adult dentate subgranular proliferative zone (Parent et al., 1997). The animals in this study undergo $6 \mathrm{~h}$ of pure electrical activation, but they have little or no injury in hippocampus. Thus, these authors preclude the possibility of injury-induced neurogenesis. However, it is unclear whether enhanced neurogenesis results in structure changes and recurrent seizures. From a regenerative standpoint, the results indicate that electrical currents could be engineered to provide directional attractive cues for driving NSC migration or regulating other cell behaviors.

Here come two questions. Whether exogenous electrical fields (EFs) can imitate endogenous signals? Can NSCs exhibit similar response to exogenous electrical cues?

\section{EXOGENOUS ELECTRICAL CURRENTS MOBILIZE NSCs/NPCs IN VITRO MODELS}

It is well established that exogenous EFs have a positive influence on cell migration known as galvanotaxis or electrotaxis since 1980s. More specifically, the cultured neural crest cells and embryonic cells move toward the cathode under the stimulation of electrical cues (Nuccitelli and Erickson, 1983; Stump and Robinson, 1983). Later studies have revealed that cathodedirected galvanotaxis is also applied to NSCs and NPCs. It suggests that EFs can guide NSCs to the lesion sites and then facilitates neural reconstruction. Several publications have shown that EFs direct migration of neonatal and adult mammalian NPCs/NSCs cathodally in a voltage or duration manner (Li et al., 2008; Ariza et al., 2010; Meng et al., 2011; Liu et al., 2015b). The major difference among these publications is the various signaling pathways mediating cell mobilization. NMDAR/Rac1/ actin (Li et al., 2008), PI3K/Akt (Meng et al., 2011), and Wnt/ GSK3 $\beta$ (Liu et al., 2015b) are involved in the complex processes, indicating that the action behind galvanotaxis is so complicated that investigators only find the tip of the iceberg. 
The differentiation of cultivated NPCs/NSCs into neurons is also being amplified with exposure to ES (Li et al., 2008; Ariza et al., 2010; Feng et al., 2012; Kobelt et al., 2014). Li et al. (2008) first testified that $68 \%$ of the migrating NPCs generate immature neurons under the influence of EFs. A recent report revealed that EFs boost more mature neuronal differentiation with the help of EFs and biochemical mediums like interferon- $\gamma$ (IFN- $\gamma$ ) (Kobelt et al., 2014). IFN- $\gamma$ is a neuronal maturation factor, and the differentiation rate of NSCs is enhanced by ES. This gives hints that chemical means can be applied to NSC mobilization.

Electrical stimulation facilitates NSCs/NPCs to migrate directionally and differentiate into neurons ex vivo, which paves the way to regenerative medicine for CNS disorders in vivo.

\section{EXOGENOUS ELECTRICAL CURRENTS MOBILIZE NSCs/NPCs IN VIVO MODELS}

Although the aforementioned findings have revealed that electrotaxis and electricity-stimulated differentiation exist in vitro, they are insufficient to illustrate the actual effects of ES on NSCs/ NPCs in CNS regeneration. For example, when NSCs/NPCs are in a more complex microenvironment in vivo, astrocytes become activated, resume proliferating, and form glia scar, which restrict neural regeneration (Yiu and $\mathrm{He}, 2006$ ) following injuries. If possible, results should be confirmed in the further animal experiments and even human trials.

\section{Effects of Invasive Electrical Stimulation on NSCs/NPCs \\ Deep-Brain Stimulation}

Invasive ES always involves the usage of an electrode implantation into the brain or neuromuscle. DBS, one of the most widely investigated invasive ES, is applied in many neurological disorders, as Parkinson's disease (PD), depression. However, the neurobiological mechanisms remain largely elusive. Some researchers propose that it potentially increases hippocampal neurogenesis. Preclinical data (Table 1) have already shown that rodents suffering from dementia, stroke, and depression have significant behavioral amelioration by DBS-induced promotion of neurogenesis (Morimoto et al., 2011; Stone et al., 2011; Schmuckermair et al., 2013; Jeong et al., 2014; Liu et al., 2015a). For example, some authors reported that improvements of cognitive function are facilitated by the stimulation of medial septum (Jeong et al., 2014), ventromedial prefrontal cortex (vmPFC) (Liu et al., 2015a), and entorhinal cortex (Stone et al., 2011), and others demonstrated the stimulation of nucleus accumbens that relieves anxiolytic symptoms (Schmuckermair et al., 2013).

In 2015, Liu et al. (2015a) studied whether vmPFC ES improves neuroplasticity in rats with age-related memory deficits. At the molecular level, genes (NeuN, Dcx, Angpt2, and S100a4) related with neurogenesis, neuronal differentiation, and migration in the neurogenic zones are upregulated. At the cellular level, a noticeable increase of C-Fos (a marker of neuronal activity) positive cells, which are Brdu/Dcx double-labeled, are observed, suggesting that newborn cells may contribute positive effects to better memory. Co-localization of BrdU and DCX in the hippocampus
TABLE 1 | Overviews of recent DBS and FES studies on NSC behavior.

\begin{tabular}{|c|c|c|c|}
\hline Reference & Intervention & Human/animal model & $\begin{array}{l}\text { Areas of } \\
\text { stimulation }\end{array}$ \\
\hline $\begin{array}{l}\text { Liu et al. } \\
\text { (2015a) }\end{array}$ & DBS & $\begin{array}{l}\text { Rat model of age-related } \\
\text { dementia }\end{array}$ & $\begin{array}{l}\text { Ventromedial } \\
\text { prefrontal } \\
\text { cortex }\end{array}$ \\
\hline $\begin{array}{l}\text { Jeong et al. } \\
(2014)\end{array}$ & DBS & Rat model of dementia & Medial septum \\
\hline $\begin{array}{l}\text { Vedam-Mai } \\
\text { et al. (2014) }\end{array}$ & DBS & Parkinson's patients & $\begin{array}{l}\text { Gpi or STN or } \\
\text { VIM }\end{array}$ \\
\hline $\begin{array}{l}\text { Schmuckermair } \\
\text { et al. (2013) }\end{array}$ & DBS & $\begin{array}{l}\text { Rat model of high anxiety } \\
\text { and depression }\end{array}$ & $\begin{array}{l}\text { Nucleus } \\
\text { accumbens }\end{array}$ \\
\hline $\begin{array}{l}\text { Morimoto et al. } \\
(2011)\end{array}$ & DBS & $\begin{array}{l}\text { Rat model of ischemic } \\
\text { stroke }\end{array}$ & Striatal \\
\hline $\begin{array}{l}\text { Stone et al. } \\
(2011)\end{array}$ & DBS & Rats & $\begin{array}{l}\text { Entorhinal } \\
\text { cortex }\end{array}$ \\
\hline $\begin{array}{l}\text { Xiang et al. } \\
(2014)\end{array}$ & FES & $\begin{array}{l}\text { Rat model of cerebral } \\
\text { infarction }\end{array}$ & $\begin{array}{l}\text { Paralyzed right } \\
\text { forelimbs }\end{array}$ \\
\hline Liu et al. (2013) & FES & Rat model of stroke & $\begin{array}{l}\text { Paralyzed } \\
\text { forelimbs }\end{array}$ \\
\hline
\end{tabular}

\begin{tabular}{|c|c|}
\hline & Results \\
\hline $\begin{array}{l}\text { Liu et al. } \\
\text { (2015a) }\end{array}$ & $\begin{array}{l}\text { Upregulates neurogenesis-related genes and NPC } \\
\text { proliferation }\end{array}$ \\
\hline $\begin{array}{l}\text { Jeong et al. } \\
(2014)\end{array}$ & Increases cholinergic activity and neurogenesis \\
\hline $\begin{array}{l}\text { Vedam-Mai } \\
\text { et al. (2014) }\end{array}$ & Increases cellular plasticity \\
\hline $\begin{array}{l}\text { Schmuckermair } \\
\text { et al. (2013) }\end{array}$ & Enhances neurogenesis \\
\hline $\begin{array}{l}\text { Morimoto et al. } \\
(2011)\end{array}$ & Facilitates neurogenesis and angiogenesis \\
\hline $\begin{array}{l}\text { Stone et al. } \\
(2011)\end{array}$ & Increases neurogenesis and spatial memory \\
\hline $\begin{array}{l}\text { Xiang et al. } \\
(2014)\end{array}$ & Increases the number of NPCs \\
\hline Liu et al. (2013) & Modulates neurogenesis \\
\hline
\end{tabular}

GPi, internal segment of the globus pallidus; STN, subthalamic nucleus; VIM, ventrointermediate nucleus of the thalamus.

represents proliferation of NPCs. Besides proliferation, Stone et al. and Schmuckermair et al. found that DBS increases the viability of newborn neurons. Schmuckermair et al. (2013) found that BrdU-positive cells are obviously more in the group when BrdU was injected before DBS than that BrdU injected during stimulation, which result from DBS increasing survival rates of cells. Stone et al. (2011) also demonstrated that DBS promotes the survival of 10-day-old neurons before stimulation in the dentate gyrus. Critically, memory improvement is neurogenesisdependent, for the effects can be blocked by temozolamide, a known inhibitor of neurogenesis (Stone et al., 2011).

However, enhanced anxiety-related mice do not respond sensitively to selective-serotonin reuptake inhibitors, while normal anxiety-related mice do (Schmuckermair et al., 2013). Thus, the reliability of enhanced anxiety-related animal models needs verification. Since the response to ES is dependent on time, voltage, interspecies, tissue origins, and others, investigators cannot deduce analogous neural plasticity in human from animal experiments. Short-duration stimulation is involved in the basic experiments, whereas sustained stimulation is applied in 
clinical settings (Stone et al., 2011). Whether chronic stimulation strengthens neurogenesis remains explored. Vedam-Mai et al. enrolled a total of 12 PD-DBS tissue samples from patients with idiopathic Parkinson's disease who received electrode placement for about $0.5-6$ years before death, which ruled out the possibility of puncture impairment-elicited neurogenesis. They first discovered NPCs increased by two to six times in the SVZ of PD-DBS brains compared with normal and untreated PD ones (VedamMai et al., 2014). In addition, other possible mechanisms, like modulation of network activity and synaptic inhibition, may attribute to the effects of DBS. So the authors could not conclude that symptomatic relief in PD-DBS patients is resulted from the proliferation of NSCs. Nevertheless, DBS has vital implications for endogenous repair of the impaired brain.

\section{Functional Electrical Stimulation}

Functional Electrical Stimulation (FES) uses electrical currents to restore the function of the paralyzed muscles caused by SCI, stroke, and other neurological diseases. The improvements of neurological deficits may be due to FES-augmented CNS regeneration (Table 1), at least to a certain extent. Xiang and his coworkers observed that FES increases the number of NPCs in the known neurogenic niches in acute stroke rats (Xiang et al., 2014). Also, FES upregulates the expression of epidermal growth factor and basic fibroblasts growth factor, which stimulate the proliferation of NSCs/NPCs. Interestingly, given that these neural factors and NPCs peak at 7 days in the FES group, the factors may have a synergic role in FES-boosted neural plasticity. Another study also indicated that FES is beneficial for protecting cortical functions partly because it supports the reorganization of neural tissue and compensates for the lost neurons in ischemic conditions (Liu et al., 2013).

\section{Electroacupuncture}

Different from DBS and FES, electroacupuncture (EA) does not involve electrode implantation. EA is the combination of traditional acupuncture and a small electric current to achieve functional recovery by stimulating certain acupoints. The electric current is generated by a device, which is attached to the needles. And the needles are inserted at acupoints.

Studies have revealed that EA can improve neurobehaviors in the models of stroke (Yang et al., 2005; Kim et al., 2014), Alzheimer's disease (Li et al., 2014), and SCI (Geng et al., 2015) perhaps via an increase of neurogenesis. Neurogenesis is wildly investigated in the cerebral ischemia model. A latest publication unraveled the molecular mechanism underlying neural regeneration elicited by EA (Kim et al., 2014) after stroke. Kim et al. tested that EA enhances the proliferation of NSCs in conjunction with increased mRNA expression and protein level, such as brainderived neurotrophic factor (BDNF) and vascular endothelial growth factor (VEGF). Thus, BDNF/VEGF signaling pathway might engage in the neurogenesis following EA. In another study, the effects of EA on attenuating the decrease of proliferating cells and differentiated neuroblasts have also been proved to be correlated with increasing BDNF levels (Chung et al., 2015). The data indicated that BDNF plays a definitive role in the downstream pathway of neurogenesis.

\section{Effects of Non-invasive Electrical Stimulation on NSCs/NPCs \\ Transcranial Magnetic Stimulation}

Compared with invasive ES, non-invasive electrical stimulation (NIES) does not require surgical procedures and has relative fewer side effects. It utilizes electrical or electromagnetic currents to target the brain through the scalp, leading to the change of cortical excitability, neuronal metabolisms, or neurotransmitter.

Transcranial magnetic stimulation, a commonly used NIES technique, was introduced by Barker et al. (1985) almost three decades ago. Despite the fact that TMS has received the approval from Food and Drug Administration (FDA) for clinical applications since 2008 , the underlying mechanism is largely puzzling. It is widely accepted that TMS augments cerebral physiology through balancing excitatory and inhibitory activity in specific brain regions. While a relevant research has examined that TMS strengthens neurogenesis in healthy rats (Ueyama et al., 2011). That is not in line with the findings of Czeh et al. (2002). It is assumed that non-optimal TMS parameters may partly explain the insignificant effects of TMS on hippocampal neurogenesis. The differences between these two studies are frequency (25 vs. $20 \mathrm{~Hz}$ ) and total pulses (14,000 vs. 5400 pulses), suggesting that more powerful stimulation may be more suitable for NSC activation (Ueyama et al., 2011).

In the subsequent studies, TMS can promote neurogenesis under pathological conditions, accompanied by behavior improvements (Guo et al., 2014; Zhang et al., 2014). Zhang et al. demonstrated the mechanism of deep-brain magnetic stimulation, a new non-invasive way applying a modified TMS protocol. Therefore, we classified deep-brain magnetic stimulation as TMS. Zhang and his colleagues provided evidence that TMS not only boosts the number of NPCs in a rat model of stress disorders but also facilitates the dendritic development of newborn neurons, implying that newborn neurons may probably integrate into existing neural networks (Zhang et al., 2014). How does TMS influence neurogenesis? Actually, little work has explored the mechanisms of TMS on neurogenesis. Guo et al. (2014) conducted a preliminary study, which revealed that miR-25-dependent p57 participates in the upregulation of NSCs induced by TMS in rats with cerebral ischemia. Although miR-25/p57 pathway does involve in the mobilization of TMS on NSCs, it is necessary to explore the comprehensive mechanisms. So, TMS can be a potential strategy for neural regeneration.

In some animal experiments, TMS could promote neural plasticity whether such effects can also be observed in human trials that remain to be examined. A recent clinical trial has shown that there are also similar therapeutic effects on depressed patients. Different from previous animal investigations, the clinical trial conducted by Furtado et al. (2013) measures neurogenesis by comparing the volume of hippocampal, amygdale, and entorhinal cortex before and after TMS using magnetic resonance imaging. Increased amygdala volumes and unchanged hippocampus volumes are found in TMS responders. There is evidence that volumetric increases are associated with structural plasticity in the CNS (Joshi et al., 2015) and neurogenesis also takes place in the amygdala (Hamilton et al., 2008). However, it is not clear 
whether the volumetric changes are induced by TMS or psychotropic medications, in that the study did not have a control group and all the enrolled individuals took the medications. Given that volumetric assessment was conducted 3 months later to ensure mood improvements, it is still unknown whether TMS direct enhances plasticity or improved mood leads to structural alterations. So, the relationship between nerve regeneration and TMS should deserve sustained attention in future.

\section{Transcranial Direct Current Stimulation}

Transcranial direct current stimulation, another commonly used NIES technique, was introduced by Priori et al. (1998) and Nitsche and Paulus (2000) following TMS. This technique delivers low currents to the brain areas of interest through electrodes over the scalp and then ameliorates negative symptoms of CNS illness by altering cortical excitability. Additionally, it is indicated that the neural regeneration can be promoted by the tDCS, thereby resulting in the improvement of neurological function.

Since fewer studies on NSC activation triggered by tDCS have been published, the level of evidence is lower than that of TMS. Rueger et al. (2012) confirmed that cathodal tDCS elicits regenerative response in stimulated hemisphere in a polarity- and session-dependent manner. Data showed that the cathodal tDCS significantly expands NSC numbers by $\sim 60 \%$ due to facilitated proliferation and migration of endogenous NSCs. In a more recent study, tDCS promotes the mobility of exogenous NSCs, which is validated by MRI and immunohistochemistry (Keuters et al., 2015). Though anodal tDCS induces an almost double increase in the migratory activity of engrafted NSCs compared with sham and cathodal stimulation group, the migration is undirected. The cell migration distance is about $1.5 \mathrm{~mm}$, which is shorter than that caused by chemotactic stimulation. The authors assumed that short-range migrating capability of implanted NSCs is restrained by the surrounding microenvironment. Perhaps, the mobility of endogenous NSCs is more susceptible to galvanotactic clues. It is worth to note that previous studies have documented that ES attracts cultured NSCs/NPCs to migrate to the cathode (Li et al., 2008; Ariza et al., 2010; Meng et al., 2011; Liu et al., 2015b). It is not consistent with the findings of Keuters and his teammates. These findings need to be replicated, and more research needs to conduct to understand how tDCs affects the migration of NSCs, and unravel their underlying electrophysiological mechanisms.

\section{DISCUSSION AND FUTURE DIRECTION}

Preclinical observations suggest that adult brain can compensate for some lost neurons or tissues via enhanced endogenous activated neurogenesis or NSCs grafts. NSCs are through three distinct steps, namely proliferation, migration, and differentiation, to replenish the damaged neurons or tissues. Actually, the greatest challenges concerning application of NSCs are not only long-term cell survival, but also low proliferation, differentiation, and migration rates. There is ample evidence illustrating these hurdles. Given the complexity of CNS microenvironment, though NSCs are transplanted into an ischemic rat model, they just survive robustly (about 33.4\%) when transplanted at medial coordinates while few cells survive at lateral coordinates (Kelly et al., 2004).
Compared with medial coordinates, lateral coordinates are closer to lesion core. Another study reported a relatively lower viability rate, from 2 to $8 \%$ (Nakagomi et al., 2009). Even though NSCs survive, they have to differentiate to functional neurons to take effect. Yet, only $0.2 \%$ newly born neurons survive at 6 weeks following ischemia insult (Arvidsson et al., 2002), as demonstrated by Arvidsson and his coworkers. So, it is necessary to improve the poor-survival rate of newborn cells before NSC-based strategy can be applied in the clinical settings. With regard to differentiation rate, it was detected that only $6 \%$ astrocytes and no neurons present in the cortex and subcortex (Zhang et al., 2001). Finally, although Kelly et al. (2004) uncovered that transplanted NSCs migrate certain distance (about $1.2 \mathrm{~mm}$ ) from the graft toward the lesion, they did not mention migration rate. However, other data presented that only $22.7 \%$ of surviving NSCs migrate away from the transplantation region (Muraoka et al., 2006). As outlined above, researchers should introduce efficient methods to increase viability, differentiation, and migration properties of NSCs, overcoming the above mentioned obstacles.

With the prevalence of ES application in experimental studies and clinical cases, research teams raise that it can act as an alternative modulator of NSC biology. Ongoing work has shown that ES can influence cytobiology parameters, such as growth, migration, differentiation, proliferation, and even morphology of NSCs invasively or non-invasively. Apparently, non-invasive ES has superiority over invasive ones. Most invasive ES but EA always requires implantation of a medical device with the operation of a neurosurgeon, which is time-and technology-depending. It is worthwhile to note that DBS has diminished response over time to brain stimulation. Conversely, non-invasive ES is convenient for repeated operations. Additionally, tDCS and TMS are proven to be well-tolerated, inexpensive, and safe with few adverse effects. Moreover, tDCS, a portable device with simplicity of its mode of action, offers the possibility of use as a home-based treatment (Page et al., 2015). Last but not the least, EA is minimally invasive and shares safe, efficacious, and inexpensive similarities with TMS and tDCS. Under comprehensive consideration, it is postulated that EA, tDCS, and TMS have more potential to activate NSCs in CNS.

Similar to ES, biomaterial engineering in enhancing regenerative potential of CNS has also been documented. Biomaterials, such as electrically conductive substrates (polymers and nanomaterials), have gradually earned attention. NSCs cultured on nanomaterials, namely carbon nanotubes, sprout more neuritis, and have a higher percentage of neuronal differentiation than those on conventional tissue culture plates (Huang et al., 2012). In an example of polymers used as substrates, neurons obtained under presence of ES are approximately 10\% higher than that in ES absence (Pires et al., 2015). No multipotent factors directing differentiation toward neuron lineage are added to culture medium. Summing up, these biomaterials exert an impact on cultivated NSC differentiation, which is innovative while is still in its infancy. More work is needed to elucidate how biomaterials drive cellular changes in the following years.

Since physical stimuli do play an instructive role in neurogenesis, do chemical stimuli facilitate regenerative capacity of CNS? Growing evidences reveal that drug-like molecules regulate 
TABLE 2 | Major studies investigating the effects of TMS, tDCS, and EA on NSCs.

\begin{tabular}{|c|c|c|c|c|}
\hline Reference & Intervention & Human/animal model & Areas of stimulation & Parameters \\
\hline Guo et al. (2014) & TMS & Rat model of stroke & Primary motor cortex & 300 pulses, 10 Hz, 3 s 120\% M \\
\hline Zhang et al. (2014) & TMS & Rat model of depression & & 20 pulses, $200 \mathrm{~Hz}$ \\
\hline \multirow[t]{2}{*}{ Furtado et al. (2013) } & TMS & Depressive patients & Left DLPFC & 35 trains, $10 \mathrm{HZ}, 120 \% \mathrm{M}$ \\
\hline & & & Bilateral DLPFC & 31 trains, $1 / 10 \mathrm{~Hz}, 120 \% \mathrm{M}$ \\
\hline Ueyama et al. (2011) & TMS & Normal rats & & 4 trains, $25 \mathrm{~Hz}, 10 \mathrm{~s}, 1000$ pulses \\
\hline Keuters et al. (2015) & tDCs & Normal rats & & Cathodal/anodal, $500 \mu \mathrm{A}, 15 \mathrm{~min}$ \\
\hline Rueger et al. (2012) & tDCS & Normal rats & & Cathodal/anodal, $500 \mu \mathrm{A}, 15 \mathrm{~min}$ \\
\hline Geng et al. (2015) & EA & Rat model of SCl & Dazhui and Mingmen & $2 \mathrm{~Hz}, 2 \mathrm{~V}, 30 \mathrm{~min}$ \\
\hline Chung et al. (2015) & EA & Rat model of diabetes & Zusanliand Baihui & $5 / 20 \mathrm{~Hz}, 2-4 \mathrm{~mA}, 20 \mathrm{~min}$ \\
\hline Kim et al. (2014) & EA & Rat model of stroke & Baihui and Dazhui & $2 \mathrm{~Hz}, 2 \mathrm{~V}, 20 \mathrm{~min}$ \\
\hline \multirow[t]{2}{*}{ Li et al. (2014) } & EA & Rat model of $A D$ & Baihui & 2/15 Hz, $1 \mathrm{~mA}, 30 \mathrm{~min}$ \\
\hline & \multicolumn{2}{|l|}{ Duration } & \multicolumn{2}{|l|}{ Results } \\
\hline Guo et al. (2014) & \multicolumn{2}{|l|}{7 days } & \multicolumn{2}{|c|}{ Increases the proliferation of adult NSCs } \\
\hline Zhang et al. (2014) & \multicolumn{2}{|c|}{ Varied (depend on the purpose of experiments) } & \multicolumn{2}{|c|}{ Facilitates adult hippocampal neurogenesis and maturation } \\
\hline Furtado et al. (2013) & \multicolumn{2}{|l|}{30 days } & \multicolumn{2}{|c|}{ Increases amygdala volume and may promotes neurogenesis } \\
\hline Ueyama et al. (2011) & \multicolumn{2}{|l|}{14 days } & \multicolumn{2}{|c|}{ Increases Brdu-positive cells } \\
\hline Keuters et al. (2015) & \multicolumn{2}{|l|}{10 days } & \multicolumn{2}{|c|}{ Increases migratory activity of NSCs } \\
\hline Rueger et al. (2012) & \multicolumn{2}{|l|}{5 or 10 days } & \multicolumn{2}{|c|}{ Elicits NSC activation and modulates neuroinflammation } \\
\hline Geng et al. (2015) & \multicolumn{2}{|l|}{14 days (peak) } & \multicolumn{2}{|c|}{ Promotes the proliferation of endogenous neural stem cells } \\
\hline Chung et al. (2015) & \multicolumn{2}{|l|}{35 days } & \multicolumn{2}{|c|}{ Increases proliferating cells and differentiated neuroblasts } \\
\hline Kim et al. (2014) & \multicolumn{2}{|l|}{10 days } & \multicolumn{2}{|c|}{ Increases proliferative cells and differentiated cells } \\
\hline Li et al. (2014) & \multicolumn{2}{|l|}{20 days } & \multicolumn{2}{|l|}{ Increases neurogenesis } \\
\hline
\end{tabular}

NSC-related processes. The pharmacological manipulation aims at epigenetic modifications or signaling pathways, both of which determine NSC development by influencing the property of protein (Lairson et al., 2013). Different from gene-based therapy, epigenetics regulate gene expression but cause no changes in the DNA sequence, minimizing the risk of gene mutation. Molecules targeting at epigenetic modifications include histone methylation, DNA methylation (Swaminathan et al., 2014) as well as noncoding RNA. The Ramous lab recently reported a new-discovered long non-coding RNA. The Long non-coding RNA Pinky is a regulator of neuronal differentiation and cell amplification (Ramos et al., 2015). Signaling molecules on neurogenesis, like Notch, bone morphogenetic protein, JAK-STAT, P53, and others (Lairson et al., 2013), are another current research focus. Whether these molecules act on epigenetics or signaling pathways provide insights into complex regenerative processes.

Challenges must be overcome to achieve successful cell replacement in the brain. Fortunately, exogenous ES, biomaterials, chemical stimuli as well as other cues can control NSC behaviors (migration, viability, differentiation, and proliferation). The advantages of EA, tDCS, and TMS make them an optimum ES to restore CNS dysfunctions. Due to their electrically conductive nature, nanomaterials and polymers can respond to ES. So, we presume that electricity combined with biomaterials may improve its electrophysiological features, which is beneficial for electricity to reach functional areas of deep brain even when the electrodes are placed on the scalp. Moreover, biomaterials can change a hostile microenvironment to a friendly microenvironment as they are able to deliver trophic factors for NSCs or endogenous tissues (Mahoney and Anseth, 2007). Molecules manipulate neurogenesis on one hand and depolarize cell membranes to alter the endogenous currents on the other hand. So, the use of endogenous currents induced by pharmacology is another alternative besides external ES. However, it is better to understand potency, solubility, selectivity, or pharmacokinetics of molecules prior to their application (Lairson et al., 2013). ES alone or combined with these alternative methods remains an exciting field, and decoding mechanisms behind these cues may serve to boost efficiency of neural regeneration.

\section{CONCLUSION}

This review has shown that ES leads to beneficial impacts on cultured NSC behaviors and animals models of depression, stroke, $\mathrm{AD}$, and SCI. These impacts may be related to strengthened intrinsic neurogenesis or increased extrinsic NSC viability and neuronal differentiation. Given that the limitations of current clinical therapies prevent neurological diseases from effective tissue repair and stem cell-based approaches are still in its infancy, ES holds great promise for facilitation of stem cell therapy. And ES thus promotes functional reconstruction in the CNS. Although a library of literature has presented data on the modulation of NSCs by ES, several aspects have not yet drawn adequate attentions. First, it needs to understand how ES acts on NSCs. Second, the detailed parameters of ES should be tailored for its maximized effects according to individual patient's conditions. In other words, for EA, the optimal acupoints, treatment frequency, intensity, and duration need to be clarified (Ho et al., 2014). Likewise, the applications of tDCS and TMS are also related to these parameters (Table 2). Finally, what else neural structures are activated by electricity during stimulation except NSCs and neurons? The effects of ES on glia cells, local circuits, and specific molecular targets deserve further investigations (Muller-Dahlhaus and 
Vlachos, 2013). This may be conductive to unravel the complex processes of neurogenesis at multiple levels and study the interplay between NSCs and other neural structures.

\section{AUTHOR CONTRIBUTIONS}

YH, YL, JC, HZ, and ST all participated in drafting the work. Among them, $\mathrm{YH}$ and YL made the largest contributions. We

\section{REFERENCES}

Alvarez-Buylla, A., and Lim, D. A. (2004). For the long run: maintaining germinal niches in the adult brain. Neuron 41, 683-686. doi:10.1016/ S0896-6273(04)00111-4

Ariza, C. A., Fleury, A. T., Tormos, C. J., Petruk, V., Chawla, S., Oh, J., et al. (2010). The influence of electric fields on hippocampal neural progenitor cells. Stem Cell Rev. 6, 585-600. doi:10.1007/s12015-010-9171-0

Arvidsson, A., Collin, T., Kirik, D., Kokaia, Z., and Lindvall, O. (2002). Neuronal replacement from endogenous precursors in the adult brain after stroke. Nat. Med. 8, 963-970. doi:10.1038/nm747

Banda, E., McKinsey, A., Germain, N., Carter, J., Anderson, N. C., and Grabel, L. (2015). Cell polarity and neurogenesis in embryonic stem cell-derived neural rosettes. Stem Cells Dev. 24, 1022-1033. doi:10.1089/scd.2014.0415

Barker, A. T., Jalinous, R., and Freeston, I. L. (1985). Non-invasive magnetic stimulation of human motor cortex. Lancet 325, 1106-1107. doi:10.1016/ S0140-6736(85)92413-4

Becker, D., Gary, D. S., Rosenzweig, E. S., Grill, W. M., and McDonald, J. W. (2010). Functional electrical stimulation helps replenish progenitor cells in the injured spinal cord of adult rats. Exp. Neurol. 222, 211-218. doi:10.1016/j. expneurol.2009.12.029

Boggio, P. S., Valasek, C. A., Campanha, C., Giglio, A. C., Baptista, N. I., Lapenta, O. M., et al. (2011). Non-invasive brain stimulation to assess and modulate neuroplasticity in Alzheimer's disease. Neuropsychol. Rehabil. 21, 703-716. doi :10.1080/09602011.2011.617943

Borgens, L. F., Jaffe, M. J., and Cohen, M. J. (1980). Large and persistent electrical currents enter the transected lamprey spinal cord. Proc. Natl. Acad. Sci. U.S.A. 77, 1209-1213. doi:10.1073/pnas.77.2.1209

Borsody, M. K., Yamada, C., Bielawski, D., Heaton, T., Castro, P. F., Garcia, A., et al. (2014). Effects of noninvasive facial nerve stimulation in the dog middle cerebral artery occlusion model of ischemic stroke. Stroke 45, 1102-1107. doi:10.1161/STROKEAHA.113.003243

Cao, L., Wei, R., Reid, B., Zhao, S., Pu, J., Pan, T., et al. (2013). Endogenous electric currents might guide rostral migration of neuroblasts. EMBO Rep. 14, 184-190. doi:10.1038/embor.2012.215

Chen, G., Wang, Y., Xu, Z., Fang, F., Xu, R., Wang, Y., et al. (2013). Neural stem cell-like cells derived from autologous bone mesenchymal stem cells for the treatment of patients with cerebral palsy. J. Transl. Med. 11, 21. doi:10.1186/1479-5876-11-21

Chung, J. Y., Yoo, D. Y., Im, W., Choi, J. H., Yi, S. S., Youn, H. Y., et al. (2015). Electroacupuncture at the Zusanli and Baihui acupoints ameliorates type-2 diabetes-induced reductions in proliferating cells and differentiated neuroblasts in the hippocampal dentate gyrus with increasing brain-derived neurotrophic factor levels. J. Vet. Med. Sci. 77, 167-173. doi:10.1292/ jvms.14-0400

Corti, S., Nizzardo, M., Simone, C., Falcone, M., Donadoni, C., Salani, S., et al. (2012). Direct reprogramming of human astrocytes into neural stem cells and neurons. Exp. Cell Res. 318, 1528-1541. doi:10.1016/j.yexcr.2012.02.040

Czeh, B., Welt, T., Fischer, A. K., Erhardt, A., Schmitt, W., Muller, M. B., et al. (2002). Chronic psychosocial stress and concomitant repetitive transcranial magnetic stimulation: effects on stress hormone levels and adult hippocampal neurogenesis. Biol. Psychiatry 52, 1057-1065. doi:10.1016/ S0006-3223(02)01457-9

Einstein, O., Ben-Menachem-Tzidon, O., Mizrachi-Kol, R., Reinhartz, E., Grigoriadis, N., and Ben-Hur, T. (2006). Survival of neural precursor cells in growth factor-poor environment: implications for transplantation in chronic disease. Glia 53, 449-455. doi:10.1002/glia.20305 thank Jackson Wu who is a foreign student from Southern Medical University for language editing of the manuscript.

\section{ACKNOWLEDGMENTS}

This review was supported by a grant from Department of Neurology, Zhujiang Hospital, Southern Medical University, China (2014J4100100).

Feldman, E. L., Boulis, N. M., Hur, J., Johe, K., Rutkove, S. B., Federici, T., et al (2014). Intraspinal neural stem cell transplantation in amyotrophic lateral sclerosis: phase 1 trial outcomes. Ann. Neurol. 75, 363-373. doi:10.1002/ana.24113

Feng, J. F., Liu, J., Zhang, X. Z., Zhang, L., Jiang, J. Y., Nolta, J., et al. (2012). Guided migration of neural stem cells derived from human embryonic stem cells by an electric field. Stem Cells 30, 349-355. doi:10.1002/stem.779

Furtado, C. P., Hoy, K. E., Maller, J. J., Savage, G., Daskalakis, Z. J., and Fitzgerald, P. B. (2013). An investigation of medial temporal lobe changes and cognition following antidepressant response: a prospective rTMS study. Brain Stimul. 6, 346-354. doi:10.1016/j.brs.2012.06.006

Ganat, Y. M., Silbereis, J., Cave, C., Ngu, H., Anderson, G. M., Ohkubo, Y., et al. (2006). Early postnatal astroglial cells produce multilineage precursors and neural stem cells in vivo. J. Neurosci. 26, 8609-8621. doi:10.1523/ JNEUROSCI.2532-06.2006

Geng, X., Sun, T., Li, J. H., Zhao, N., Wang, Y., and Yu, H. L. (2015). Electroacupuncture in the repair of spinal cord injury: inhibiting the Notch signaling pathway and promoting neural stem cell proliferation. Neural Regen. Res. 10, 394-403. doi:10.4103/1673-5374.153687

Guo, F., Han, X., Zhang, J., Zhao, X., Lou, J., Chen, H., et al. (2014). Repetitive transcranial magnetic stimulation promotes neural stem cell proliferation via the regulation of MiR-25 in a rat model of focal cerebral ischemia. PLoS ONE 9:e109267. doi:10.1371/journal.pone.0109267

Hamilton, J. P., Siemer, M., and Gotlib, I. H. (2008). Amygdala volume in major depressive disorder: a meta-analysis of magnetic resonance imaging studies. Mol. Psychiatry 13, 993-1000. doi:10.1038/mp.2008.57

Han, D. W., Tapia, N., Hermann, A., Hemmer, K., Hoing, S., Arauzo-Bravo, M. J., et al. (2012). Direct reprogramming of fibroblasts into neural stem cells by defined factors. Cell Stem Cell 10, 465-472. doi:10.1016/j.stem.2012.02.021

Ho, T. J., Chan, T. M., Ho, L. I., Lai, C. Y., Lin, C. H., Macdonald, I., et al. (2014). The possible role of stem cells in acupuncture treatment for neurodegenerative diseases: a literature review of basic studies. Cell Transplant. 23, 559-566. doi:1 $0.3727 / 096368914 X 678463$

Hotary, K. B., and Robinson, K. R. (1990). Endogenous electrical currents and the resultant voltage gradients in the chick embryo. Dev. Biol. 140, 149-160. doi:10.1016/0012-1606(90)90062-N

Huang, Y. J., Wu, H. C., Tai, N. H., and Wang, T. W. (2012). Carbon nanotube rope with electrical stimulation promotes the differentiation and maturity of neural stem cells. Small 8, 2869-2877. doi:10.1002/smll.201200715

Jablonska, A., Kozlowska, H., Markiewicz, I., Domanska-Janik, K., and Lukomska, B. (2010). Transplantation of neural stem cells derived from human cord blood to the brain of adult and neonatal rats. Acta Neurobiol. Exp. (Wars.) 70, 337-350.

Jahanshahi, A., Schonfeld, L., Janssen, M. L., Hescham, S., Kocabicak, E., Steinbusch, H. W., et al. (2013). Electrical stimulation of the motor cortex enhances progenitor cell migration in the adult rat brain. Exp. Brain Res. 231, 165-177. doi:10.1007/s00221-013-3680-4

Jeong, D. U., Lee, J. E., Lee, S. E., Chang, W. S., Kim, S. J., and Chang, J. W. (2014). Improvements in memory after medial septum stimulation are associated with changes in hippocampal cholinergic activity and neurogenesis. Biomed Res. Int. 2014, 568587. doi:10.1155/2014/568587

Joshi, S. H., Espinoza, R. T., Pirnia, T., Shi, J., Wang, Y., Ayers, B., et al. (2015). Structural plasticity of the hippocampus and amygdala induced by electroconvulsive therapy in major depression. Biol. Psychiatry doi:10.1016/j. biopsych.2015.02.029

Kelly, S., Bliss, T. M., Shah, A. K., Sun, G. H., Ma, M., Foo, W. C., et al. (2004). Transplanted human fetal neural stem cells survive, migrate, and differentiate in ischemic rat cerebral cortex. Proc. Natl. Acad. Sci. U.S.A. 101, 11839-11844. doi:10.1073/pnas.0404474101 
Keuters, M. H., Aswendt, M., Tennstaedt, A., Wiedermann, D., Pikhovych, A., Rotthues, S., et al. (2015). Transcranial direct current stimulation promotes the mobility of engrafted NSCs in the rat brain. NMR Biomed. 28, 231-239. doi: $10.1002 / \mathrm{nbm} .3244$

Kim, Y. R., Kim, H. N., Ahn, S. M., Choi, Y. H., Shin, H. K., and Choi, B. T. (2014). Electroacupuncture promotes post-stroke functional recovery via enhancing endogenous neurogenesis in mouse focal cerebral ischemia. PLoS ONE 9:e90000. doi:10.1371/journal.pone.0090000

Kobelt, L. J., Wilkinson, A. E., McCormick, A. M., Willits, R. K., and Leipzig, N. D. (2014). Short duration electrical stimulation to enhance neurite outgrowth and maturation of adult neural stem progenitor cells. Ann. Biomed. Eng. 42, 2164-2176. doi:10.1007/s10439-014-1058-9

Lairson, L. L., Lyssiotis, C. A., Zhu, S., and Schultz, P. G. (2013). Small molecule-based approaches to adult stem cell therapies. Annu. Rev. Pharmacol. Toxicol. 53, 107-125. doi:10.1146/annurev-pharmtox-011112-140300

Lendvai, B., Stern, E. A., Chen, B., and Svoboda, K. (2000). Experience-dependent plasticity of dendritic spines in the developing rat barrel cortex in vivo. Nature 404, 876-881. doi:10.1038/35009107

Levi, H., Schoknecht, K., Prager, O., Chassidim, Y., Weissberg, I., Serlin, Y., et al. (2012). Stimulation of the sphenopalatine ganglion induces reperfusion and blood-brain barrier protection in the photothrombotic stroke model. PLoS ONE 7:e39636. doi:10.1371/journal.pone.0039636

Li, L., El-Hayek, Y. H., Liu, B., Chen, Y., Gomez, E., Wu, X., et al. (2008). Directcurrent electrical field guides neuronal stem/progenitor cell migration. Stem Cells 26, 2193-2200. doi:10.1634/stemcells.2007-1022

Li, X., Guo, F., Zhang, Q., Huo, T., Liu, L., Wei, H., et al. (2014). Electroacupuncture decreases cognitive impairment and promotes neurogenesis in the APP/PS1 transgenic mice. BMC Complement. Altern. Med. 14:37. doi:10.1186/1472-6882-14-37

Liu, A., Jain, N., Vyas, A., and Lim, L. W. (2015a). Ventromedial prefrontal cortex stimulation enhances memory and hippocampal neurogenesis in the middle-aged rats. eLife 4:e04803. doi:10.7554/eLife.04803

Liu, J., Zhu, B., Zhang, G., Wang, J., Tian, W., Ju, G., et al. (2015b). Electric signals regulate directional migration of ventral midbrain derived dopaminergic neural progenitor cells via Wnt/GSK3beta signaling. Exp. Neurol. 263, 113-121. doi:10.1016/j.expneurol.2014.09.014

Liu, H. H., Xiang, Y., Yan, T. B., Tan, Z. M., Li, S. H., and He, X. K. (2013). Functional electrical stimulation increases neural stem/progenitor cell proliferation and neurogenesis in the subventricular zone of rats with stroke. Chin. Med. J. (Engl.) 126, 2361-2367. doi:10.3760/cma.j.issn.0366-6999.20130478

Ludemann-Podubecka, J., Bosl, K., Rothhardt, S., Verheyden, G., and Nowak, D. A. (2014). Transcranial direct current stimulation for motor recovery of upper limb function after stroke. Neurosci. Biobehav. Rev. 47, 245-259. doi:10.1016/j. neubiorev.2014.07.022

Mahoney, M. J., and Anseth, K. S. (2007). Contrasting effects of collagen and bFGF-2 on neural cell function in degradable synthetic PEG hydrogels. J. Biomed. Mater. Res. A 81, 269-278. doi:10.1002/jbm.a.30970

Meng, X., Arocena, M., Penninger, J., Gage, F. H., Zhao, M., and Song, B. (2011). PI3K mediated electrotaxis of embryonic and adult neural progenitor cells in the presence of growth factors. Exp. Neurol. 227, 210-217. doi:10.1016/j. expneurol.2010.11.002

Morimoto, T., Yasuhara, T., Kameda, M., Baba, T., Kuramoto, S., Kondo, A., et al. (2011). Striatal stimulation nurtures endogenous neurogenesis and angiogenesis in chronic-phase ischemic stroke rats. Cell Transplant. 20, 1049-1064. doi:1 $0.3727 / 096368910$ X544915

Muller-Dahlhaus, F., and Vlachos, A. (2013). Unraveling the cellular and molecular mechanisms of repetitive magnetic stimulation. Front. Mol. Neurosci. 6:50. doi:10.3389/fnmol.2013.00050

Muraoka, K., Shingo, T., Yasuhara, T., Kameda, M., Yuan, W., Hayase, H., et al. (2006). The high integration and differentiation potential of autologous neural stem cell transplantation compared with allogeneic transplantation in adult rat hippocampus. Exp. Neurol. 199, 311-327. doi:10.1016/j. expneurol.2005.12.004

Nakagomi, N., Nakagomi, T., Kubo, S., Nakano-Doi, A., Saino, O., Takata, M., et al. (2009). Endothelial cells support survival, proliferation, and neuronal differentiation of transplanted adult ischemia-induced neural stem/progenitor cells after cerebral infarction. Stem Cells 27, 2185-2195. doi:10.1002/stem.161
Nithianantharajah, J., and Hannan, A. J. (2006). Enriched environments, experience-dependent plasticity and disorders of the nervous system. Nat. Rev. Neurosci. 7, 697-709. doi:10.1038/nrn1970

Nitsche, M. A., and Paulus, W. (2000). Excitability changes induced in the human motor cortex by weak transcranial direct current stimulation. J. Physiol. 527(Pt 3), 633-639. doi:10.1111/j.1469-7793.2000.t01-1-00633.x

Nizzardo, M., Simone, C., Rizzo, F., Ruggieri, M., Salani, S., Riboldi, G., et al. (2014). Minimally invasive transplantation of iPSC-derived ALDHhiSSCloVLA4+ neural stem cells effectively improves the phenotype of an amyotrophic lateral sclerosis model. Hum. Mol. Genet. 23, 342-354. doi:10.1093/hmg/ddt425

Nuccitelli, R., and Erickson, C. A. (1983). Embryonic cell motility can be guided by physiological electric fields. Exp. Cell Res. 147, 195-201. doi:10.1016/0014-4827(83)90284-7

Page, S. J., Cunningham, D. A., Plow, E., and Blazak, B. (2015). It takes two: noninvasive brain stimulation combined with neurorehabilitation. Arch. Phys. Med. Rehabil. 96, S89-S93. doi:10.1016/j.apmr.2014.09.019

Parent, J. M., Yu, T. W., Leibowitz, R. T., Geschwind, D. H., Sloviter, R. S., and Lowenstein, D. H. (1997). Dentate granule cell neurogenesis is increased by seizures and contributes to aberrant network reorganization in the adult rat hippocampus. J. Neurosci. 17, 3727-3738.

Pienaar, I. S., Lee, C. H., Elson, J. L., McGuinness, L., Gentleman, S. M., Kalaria, R. N., et al. (2015). Deep-brain stimulation associates with improved microvascular integrity in the subthalamic nucleus in Parkinson's disease. Neurobiol. Dis. 74, 392-405. doi:10.1016/j.nbd.2014.12.006

Pires, F., Ferreira, Q., Rodrigues, C. A., Morgado, J., and Ferreira, F. C. (2015). Neural stem cell differentiation by electrical stimulation using a cross-linked PEDOT substrate: expanding the use of biocompatible conjugated conductive polymers for neural tissue engineering. Biochim. Biophys. Acta 1850, 1158-1168. doi:10.1016/j.bbagen.2015.01.020

Priori, A., Berardelli, A., Rona, S., Rona, S., Accornero, N., Accornero, N., et al. (1998). Polarization of the human motor cortex through the scalp. Neuroreport 9, 2257-2260. doi:10.1097/00001756-199807130-00020

Ramos, A. D., Andersen, R. E., Liu, S. J., Nowakowski, T. J., Hong, S. J., Gertz, C. C., et al. (2015). The long noncoding RNA pnky regulates neuronal differentiation of embryonic and postnatal neural stem cells. Cell Stem Cell 16, 439-447. doi:10.1016/j.stem.2015.02.007

Reynolds, B. A., and Weiss, S. (1992). Generation of neurons and astrocytes from isolated cells of the adult mammalian central nervous system. Science 255, 1707-1710. doi:10.1126/science. 1553558

Rueger, M. A., Keuters, M. H., Walberer, M., Braun, R., Klein, R., Sparing, R., et al. (2012). Multi-session transcranial direct current stimulation (tDCS) elicits inflammatory and regenerative processes in the rat brain. PLoS ONE 7:e43776. doi:10.1371/journal.pone.0043776

Sackeim, H. A., Prudic, J., Devanand, D. P., Nobler, M. S., Lisanby, S. H., Peyser, S., et al. (2000). A prospective, randomized, double-blind comparison of bilateral and right unilateral electroconvulsive therapy at different stimulus intensities. Arch. Gen. Psychiatry 57, 425-434. doi:10.1001/archpsyc.57.5.425

Salewski, R. P., Mitchell, R. A., Shen, C., and Fehlings, M. G. (2015). Transplantation of neural stem cells clonally derived from embryonic stem cells promotes recovery after murine spinal cord injury. Stem Cells Dev. 24, 36-50. doi:10.1089/ scd.2014.0096

Schmuckermair, C., Gaburro, S., Sah, A., Landgraf, R., Sartori, S. B., and Singewald, N. (2013). Behavioral and neurobiological effects of deep brain stimulation in a mouse model of high anxiety- and depression-like behavior. Neuropsychopharmacology 38, 1234-1244. doi:10.1038/npp.2013.21

Smith, D. C., Modglin, A. A., Roosevelt, R. W., Neese, S. L., Jensen, R. A., Browning, R. A., et al. (2005). Electrical stimulation of the vagus nerve enhances cognitive and motor recovery following moderate fluid percussion injury in the rat. J. Neurotrauma 22, 1485-1502. doi:10.1089/neu.2005.22.1485

Stone, S. S., Teixeira, C. M., Devito, L. M., Zaslavsky, K., Josselyn, S. A., Lozano, A. M., et al. (2011). Stimulation of entorhinal cortex promotes adult neurogenesis and facilitates spatial memory. J. Neurosci. 31, 13469-13484. doi:10.1523/ JNEUROSCI.3100-11.2011

Stump, R. F., and Robinson, K. R. (1983). Xenopus neural crest cell migration in an applied electrical field. J. Cell Biol. 97, 1226-1233. doi:10.1083/jcb.97.4.1226 Swaminathan, A., Kumar, M., Halder, S. S., Schneider-Anthony, A., Boutillier, A. L., and Kundu, T. K. (2014). Modulation of neurogenesis by targeting 
epigenetic enzymes using small molecules: an overview. ACS Chem. Neurosci. 5, 1164-1177. doi:10.1021/cn500117a

Tang, Y., Wang, J., Lin, X., Wang, L., Shao, B., Jin, K., et al. (2014). Neural stem cell protects aged rat brain from ischemia-reperfusion injury through neurogenesis and angiogenesis. J. Cereb. Blood Flow Metab. 34, 1138-1147. doi:10.1038/ jcbfm.2014.61

Thier, M., Worsdorfer, P., Lakes, Y. B., Gorris, R., Herms, S., Opitz, T., et al. (2012). Direct conversion of fibroblasts into stably expandable neural stem cells. Cell Stem Cell 10, 473-479. doi:10.1016/j.stem.2012.03.003

Ueyama, E., Ukai, S., Ogawa, A., Yamamoto, M., Kawaguchi, S., Ishii, R., et al. (2011). Chronic repetitive transcranial magnetic stimulation increases hippocampal neurogenesis in rats. Psychiatry Clin. Neurosci. 65, 77-81. doi:10.1111/j.1440-1819.2010.02170.x

Vedam-Mai, V., Gardner, B., Okun, M. S., Siebzehnrubl, F. A., Kam, M., Aponso, P., et al. (2014). Increased precursor cell proliferation after deep brain stimulation for Parkinson's disease: a human study. PLOS ONE 9:e88770. doi:10.1371/ journal.pone.0088770

Wang, J., Dong, W. W., Zhang, W. H., Zheng, J., and Wang, X. (2014). Electrical stimulation of cerebellar fastigial nucleus: mechanism of neuroprotection and prospects for clinical application against cerebral ischemia. CNS Neurosci. Ther. 20, 710-716. doi:10.1111/cns.12288

Xiang, Y., Liu, H., Yan, T., Zhuang, Z., Jin, D., and Peng, Y. (2014). Functional electrical stimulation-facilitated proliferation and regeneration of neural precursor cells in the brains of rats with cerebral infarction. Neural Regen. Res. 9, 243-251. doi:10.4103/1673-5374.128215

Yang, Z. J., Shen, D. H., Guo, X., Guo, X., Sun, F., and Sun, F. Y. (2005). Electroacupuncture enhances striatal neurogenesis in adult rat brains after a transient cerebral middle artery occlusion. Acupunct. Electrother. Res. 30, 185-199.

Yiu, G., and He, Z. (2006). Glial inhibition of CNS axon regeneration. Nat. Rev. Neurosci. 7, 617-627. doi:10.1038/nrn1956

Zhang, R. L., Zhang, Z. G., Zhang, L., and Chopp, M. (2001). Proliferation and differentiation of progenitor cells in the cortex and the subventricular zone in the adult rat after focal cerebral ischemia. Neuroscience 105, 33-41. doi:10.1016/ S0306-4522(01)00117-8

Zhang, W., Gu, G. J., Shen, X., Zhang, Q., Wang, G. M., and Wang, P. J. (2015). Neural stem cell transplantation enhances mitochondrial biogenesis in a transgenic mouse model of Alzheimer's disease-like pathology. Neurobiol. Aging 36, 1282-1292. doi:10.1016/j.neurobiolaging.2014.10.040

Zhang, Y., Mao, R. R., Chen, Z. F., Tian, M., Tong, D. L., Gao, Z. R., et al. (2014). Deep-brain magnetic stimulation promotes adult hippocampal neurogenesis and alleviates stress-related behaviors in mouse models for neuropsychiatric disorders. Mol. Brain 7, 11. doi:10.1186/1756-6606-7-11

Conflict of Interest Statement: The authors declare that the research was conducted in the absence of any commercial or financial relationships that could be construed as a potential conflict of interest.

Copyright (c) 2015 Huang, Li, Chen, Zhou and Tan. This is an open-access article distributed under the terms of the Creative Commons Attribution License (CC BY). The use, distribution or reproduction in other forums is permitted, provided the original author(s) or licensor are credited and that the original publication in this journal is cited, in accordance with accepted academic practice. No use, distribution or reproduction is permitted which does not comply with these terms. 